Cadernos de Clio, Curitiba, n. ${ }^{\circ} 2,2011$

\title{
Inquisição portuguesa na África: Denunciações do Reino do Congo e Angola no século XVII.
}

\author{
Tahinan da Cruz Santos ${ }^{1}$
}

Resumo: O Tribunal da Santa Inquisição português foi criado com o objetivo de vigiar, investigar e punir crimes considerados heréticos, dentro da área de influência territoriais de Portugal, dentre os quais incluíam-se os Reinos do Congo e Angola. Diante disso, estudar os autos de Denunciações do reino do Congo e Angola mostra-se muito importante. Entre os anos de 1620-32, foi arrolada uma série de denúncias contra quase cem pessoas. Estas foram acusadas de judaísmo, feitiçaria, simonia e até mesmo calúnia e injúria contra o Santo Ofício. Este processo, composto por 214 páginas microfilmadas, encontra-se aos cuidados do Arquivo Nacional da Torre do Tombo. Trata-se de uma fonte riquíssima, por mostrar os tentáculos da Inquisição, assim como as crenças e o cotidiano religioso das populações européias e africanas nos Reinos do Congo e Angola.

Palavra-chave: Inquisição portuguesa; Congo e Angola; Século XVII.

\footnotetext{
${ }^{1}$ Graduanda do curso de Licenciatura em História, $8^{\circ}$ semestre. Universidade do Estado da Bahia. Campus XIII - Itaberaba. Este artigo é parte de um projeto maior, intitulado A Inquisição portuguesa no sertão da Bahia, século XVIII coordenado pela professora Dr. ${ }^{a}$ Vanicléia Silva Santos. A escrita desse artigo somente foi possível após a transcrição do processo de "Denunciações do reino do Congo e Angola". Isso com a ajuda de um curso básico de paleografia, que também é parte integrante do projeto maior. A transcrição do processo não foi totalmente concluída, o que me possibilitou apenas uma análise parcial de tal documento.
} 
Cadernos de Clio, Curitiba, n..$^{\circ}$ 2, 2011

\section{Introdução}

Durante a Idade Média, a Igreja detinha o poder político e econômico na Europa. Porém, já haviam movimentos que queriam ser contrário a esse hegemonia. De tal forma que a Igreja sentiu a necessidade de constituir medidas que estancassem essas agitações. Foi então que o papa Gregório IX (1221-1241), através de uma bula, estabeleceu a criação do Tribunal da Santa Inquisição, que regia a Europa, principalmente o sul da França (SOUZA, GMB 2009: 26). Diferente da Inquisição Medieval, que tinha um cunho exclusivamente idealizado e dominado pelo clero, a Inquisição Moderna teve esse apoio estatal, mostrando a implicação política que esta idealizava. Então, a Inquisição Moderna pretendia mesmo a centralização do poder.

O Tribunal da Santa Inquisição Moderna, portanto, tinha como objetivo vigiar, investigar e punir cristãos, que de algum modo estivessem indo de encontro aos dogmas da Igreja. Sua jurisdição se estabeleceu entre todos os domínios da cristandade. Então, somente os cristãos poderiam estar sob vigilância e punidos pela Inquisição. (SANTOS, 2008: 208).

Por mais de três séculos o Tribunal Inquisitorial agiu em Portugal. Perseguiu principalmente os cristãos novos e judeus. Estudos mostram o interesse econômico do Santo Ofício. Isso

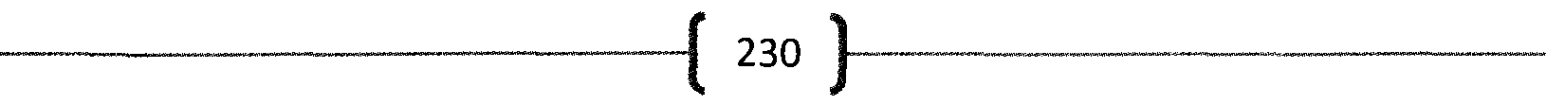


justifica a perseguição aos judeus, já que estes possuíam grandes riquezas.

(...)à citada concessão papal para o estabelecimento da Inquisição Espanhola, a alegação foi, sobretudo, o crescimento de práticas judaizantes entre os neófitos. Estes, quase sempre pertenciam a famílias bastante ricas e que, a partir do momento em que fossem condenados como hereges, certamente seus bens seriam confiscados em benefício do Estado e da Igreja - ao menos teoricamente. Como tem sido enfatizado por muitos historiadores, os recursos advindos de confíscos da Inquisição foram a mola propulsora do Tribunal, eram um incentivo que estimulava ainda mais a dedicação religiosa das autoridades civis e clericais. (SOUZA, GMB 2009:29)

A Inquisição portuguesa foi estabelecida no ano de 1536, por ordem de Dom João III, rei de Portugal. Em 23 de maio de 1536, o Papa Paulo III publicou a bula, lida em Évora, "que estabelece o Santo Ofício da Inquisição Portuguesa" (SOUZA, GMB 2009: 36). A unidade da fé era também uma das questões buscadas através da instituição inquisitorial, de modo que até então, este era um domínio exclusivamente clerical, porém, em 1547, a monarquia portuguesa obteve o poder para indicar quem faria parte do Tribunal. Anteriormente, na Inquisição Medieval, somente o papa poderia fazer essa indicação. Dessa maneira, houve a centralização do poder monárquico, assim como ocorreu na Espanha (SOUZA, GMB 2009: 36). 
Os Tribunais portugueses eram divididos em quatro, para maior abrangência da sua diligência. O mais importante, de Lisboa, no qual o Brasil e todos os domínios portugueses, até o cabo da Boa Esperança estavam inclusos. O segundo, o Tribunal de Évora. Terceiro, o de Coimbra. Quarto era o Tribunal de Goa. Este foi criado em 1560 e abrangia o território que ia desde o Cabo da Boa Esperança, a Ásia e a Costa Oriental da África. Existiram também outros tribunais, porém logo foram abolidos pela precariedade da administração e abuso de poder (SOUZA, GMB 2009: 38). Então, o Congo e a Angola faziam parte do primeiro Tribunal, o de Lisboa, conjuntamente com o Brasil.

\section{Os portugueses no Congo}

Em 1575, chega em Angola muitos europeus, com o intuito de administrar aquelas terras, acompanhados principalmente de cristãos novos, antigos judeus. A vila de São Paulo de Luanda fora fundada por Paulo Dias de Novais, quando ele chegou à Angola. Dessa forma, entende-se como se deu a cristianização dessa colônia portuguesa:

Para o padre Gouveia e seus colegas da Companhia de Jesus, só se conseguiria evangelizar os africanos, caso eles fossem antes subjugados militarmente. Não se tratava mais de fundar feitorias nem de repetir a 
Cadernos de Clio, Curitiba, n. ${ }^{0} 2,2011$

política da aliança, catequese e cooperação desenvolvida no Congo, mas de ocupar o reino do angola, para depois, de uma posição de força, convertê-lo.(SILVA, 2002: 408)

No entanto, a evangelização não se deu dessa forma, muito menos a colonização portuguesa: "Fora dos estabelecimentos portugueses e situados pela hostilidade ambuda, a catequese não dera frutos; as convenções eram de conveniência e podiam durar pouco." (SILVA, 2002: 412) Os reis angolas perceberam que os portugueses que ali atracaram, chegaram para ficar, devido às construções de igrejas e fortificações. Houveram confrontos entre os angolas e os portugueses, visto que estava em xeque uma boa parte do comércio na costa. (SILVA, 2002)

Em 1568, morreu Dom Álvaro I - rei do Congo, e o seu fillho logo o sucedeu no seu reinado. Dom Álvaro II apoiou-se em seu exército e tentou liberta-se do controle português e constituir uma Igreja Católica do Congo à parte do bispado de São Tomé. Em 1596, o papa Clemente VII, separou os dois bispados, porém, o novo bispado ficou à margem, tendo os mesmos problemas, pois quem o assumiu foi um português, e não um sacerdote local, como desejava Dom Álvaro II. Isso mostra as tentativas portuguesas de implantar uma fé católica mais condizente com a realidade do Congo, dando 
Cadernos de Clio, Curitiba, n. ${ }^{\circ} 2,2011$

maiores possibilidades de uma cristianização da população local (SILVA, 2002: 432).

José da Silva Horta, faz uma discussão acerca do Inquérito realizado em 1596-98 no Congo e Angola. Para o autor, o ouvidor do Santo Ofício em Angola tinha poderes para punir crimes de heresia. Isto porque a justiça eclesiástica e a justiça civil interferiam nos julgamentos inquisitoriais, até mesmo sem a conivência do Santo Ofício. (HORTA, 1988: 400)

o visitador da Baía, Heitor Furtado de Mendonça, por decisão do Conselho Geral, não efetuou a deslocação, inicialmente prevista ao Bispado de S. Tomé, sob cuja alçada estava o reino de Angola (...) e o envio de outro visitador sairia muito dispêndios. (...) a solução institucional para o caso teve de passar pela nomeação de um religioso que residisse no próprio reino de Angola. (HORTA, 1988: 388)

Dessa forma, o escolhido teria poderes para recolher as denúncias, efetuar as prisões e enviar os acusados à Inquisição de Lisboa. Essa certa independência era de suma importância para as colônias portuguesas, visto que dessa forma, poderiam supervisionar e controlar melhor a população cristã nesses territórios. (SOUZA, GMB 2009: 32) 


\section{Denunciações do Reino do Congo e Angola}

O documento classificado como processo, Denunciações do Reino do Congo e Angola, foi registrado entre os anos de 1620 a 1632 e encontra-se sob tutela do Instituto Arquivos Nacionais da Torre do Tombo, em Lisboa, Portugal. Trata-se de denúncias que foram reunidas pelos padres. E por tratar-se apenas de denúncias e não de um inquérito, este processo não contém o que os inquéritos normais tinham: admoestação, sumário de culpas e principalmente as sentenças. Este processo estava sob responsabilidade inicial do Padre Jerônimo Vogado, comissário do Santo Ofício, Manoel da Silva, familiar; e Manoel Bernardes, secretário do Santo Ofício (IANTT, DRCA, mç. 9, doc 8$)^{2}$.

Estruturalmente, o Santo Ofício funcionava da seguinte maneira, onde havia Tribunais físicos: Inquisidores; deputados; promotores; notários; procuradores; solicitadores; qualificadores; meirinhos; alcaide dos cárceres; porteiro da mesa do despacho; dispenseiro e guardas necessários. Onde não havia a presença física de um Tribunal, poderia funcionar dessa forma: padre; pároco; familiar, que eram em sua maioria leigos e sua função era de manter os comissários informados sobre os acontecimentos que seriam da

\footnotetext{
${ }^{2}$ Instituto Arquivo Nacional da Torre do Tombo (IANTT). Denunciações do Reino do Congo e Angola (DRCA). Ao longo do artigo, usarei apenas a abreviação IANTT para referenciar o Instituto Arquivo Nacional da Torre do Tombo e DRCA para Denunciações do Reino do Congo e Angola.
} 
responsabilidade do Santo Ofício averiguar; e comissário: era o cargo mais alto, dentro dessa hierarquia e tinha a responsabilidade de receber e encaminhar as denúncias para o Santo Ofício sendo, portanto, pessoas eclesiásticas. (SOUZA, GMB 2009: 51)

Para podermos compreender os meandros dos inquéritos, torna-se imprescindível descrever as ações que o Tribunal da Santa Inquisição julgava como crime:

Os crimes da alçada da Inquisição Portuguesa estavam divididos em duas categorias. De um lado, os crimes contra a fé - judaísmo, maometismo, protestantismo, molinismo, deísmo, libertinismo, críticas aos dogmas, etc. -, considerados de maior gravidade pela Igreja e que resultavam em punições mais rigorosas para os réus. De outro lado, os crimes contra a moral e os costumes - bigamia, sodomia, feitiçaria, solicitação que em alguns casos se confundiam com os primeiros, contudo geralmente percebidos como de menor gravidade e consequentemente, passíveis de penas menos severas. (SOUZA, 2009: 37)

Desse modo, poderemos analisar com maior propriedade as denúncias e inquirições feitas pelo Santo Ofício, como também os seus julgamentos e penas. No entanto, essa análise não é objetivo neste trabalho. Nosso maior escopo, está em compreender as questões ligadas ao cotidiano e a religiosidade dos habitantes do Congo e Angola do século XVII. 
Composto por 214 fólios, sendo 65 fólios $\mathrm{em}$ branco, as Denunciações do Reino do Congo e Angola, reúne acusações de vários crimes: desde aqueles cometidos contra a fé, até os crimes contra a moral e os costumes. Trata-se de denúncias que foram reunidas pelos padres do Santo Ofício, no qual aparecem relatos contra africanos como também denunciantes negros. (IANTT DRCA, mç. 9, doc $8:$ 144) Divergindo destas informações, está o trabalho de José Augusto da Silva Horta, com A Inquisição em Angola e Congo: O Inquérito de 1596-98 e o papel mediador das justiças locais. Tendo um total de 96 denunciados, o Inquérito não faz menção a denunciantes ou denunciados nativos do Congo e Angola. (HORTA, 1988: 387)

Examinando um primeiro exemplo das Denunciações do Reino do Congo e Angola, temos o caso de Manoel Cardoso, cristão novo, de mais ou menos 23 anos de idade. Foi denunciado por Miguel, cristão velho, mais ou menos 54 anos de idade. Miguel acusou-o de ter dito que a casa do Santo Ofício era casa do inferno e que estes só sabiam tomar as fazendas alheias (IANTT DRCA, mç. 9, doc $8: 114$ ). Este relato nos pode esclarecer como a população via os confiscos realizados pelo Santo Ofício, resultado da punição pelos crimes cometidos. Fernandes Barbosa, que também foi denunciado para o Santo Ofício por proferir palavras injuriosas 
contra os inquisidores, difamando-os (IANTT DRCA, mç. 9, doc 8 : 90).

É relevante também perceber a rivalidade existente entre cristãos novos e cristãos velhos. Horta, em sua análise, disserta que, boa parte dos denunciados constitui-se de cristãos novos. Em contrapartida, é bem significativo o número de cristãos velhos denunciantes (HORTA, 1988: 392). Nas Denunciações do Reino do Congo e Angola, podemos perceber isso claramente. Boa parte das denúncias é feita por cristãos velhos. É feita uma investigação pelos padres da inquisição, para saber a origem dos denunciantes através de um formulário de perguntas. Como também procura-se saber se são cristãos novos ou velhos, os denunciados.

No desenrolar das Denunciações do Reino do Congo $e$ Angola, encontra-se uma passagem, no qual o padre Luis Peres da Veiga é mandado pelo Inquisidor Geral em setembro de 1626, para visitar o reino de Angola. O objetivo dessa visitação era relembrar aos padres como deveriam proceder com as denúncias. Foram registradas as perguntas que deveriam ser feitas aos denunciantes, como também fora colocado a brevidade que os casos deveriam ser enviados para o Inquisidor Geral (IANTT DRCA, mç. 9, doc 8: 196). Então, existia um procedimento padrão para guiar as práticas inquisitoriais. 
Nas Denunciações há um caso de crime contra a moral e os costumes $^{3}$. Foi o caso de um homem chamado Domingos Ambundo Maia (IANTT DRCA, mç. 9, doc 8 : 132), que foi denunciado por Dom Paulo Afonso, trinta anos mais ou menos, casado, morador da cidade do Congo. O caso se deu em maio de 1628 e o denunciante revelou detalhes do rito que assistiu, além de confessar que foi curado durante este rito. Ele diz que Domingos estava cozendo uma panela de ervas e colocou dentro dela, a figura de um homem feita de pau. Isso aconteceu em meio a uma reunião, na qual estavam presentes muitas pessoas, inclusive escravos e mulheres.

Esta denúncia, que foi feita ao dia 08 de maio de 1628 , revela as relações existentes entre escravos, mulheres e talvez homens brancos. Podemos afirmar isso, porque possivelmente o denunciante Dom Paulo Afonso, seria um homem branco, e tinha conhecimento do que acontecia nessas reuniões geridas pelo tal Domingos. Porém, o próprio Dom Paulo Afonso tratou de esclarecer sobre as suas crenças, corroborando que nem ele, nem os demais presentes teriam adorado a figura de homem feita de pau:

(...) E que não sabe, se o dito Domingos tinha aquela figura por Deus. Porém que ele dito dom Paulo sabia muito bem que aquilo era tudo (...), e que a figura não

\footnotetext{
${ }^{3}$ Considerado pelo regime do Santo Oficio, como de menor gravidade, cujas penas
} eram mais brandas. 
Cadernos de Clio, Curitiba, n. ${ }^{\circ} 2,2011$

era Deus, nem tinha muito de (...) de saúde. E que nem o dito Domingos, nem ele Paulo nem outro alguém pessoas das que ali se acharam, adoraram a dita figura $^{4}$. (IANTT DRCA, mç. 9, doc $8: 132$ )

Neste processo, existe também uma denúncia relativa a uma bolsa de mandinga. ${ }^{5}$ Esta referia-se a Nicolau Miguel, denunciado por crime de feitiçaria (IANTT DRCA, mç. 9, doc $8: 18$ ). O denunciado tinha em sua posse, uma bolsa, na qual continha uma partícula e outras relíquias, que segundo denunciante - Manuel Correa, natural da cidade do Porto, casado, com mais ou menos 35 anos de idade - a dita bolsa protegeria o denunciado caso ele brigasse e se ferisse, pois este "não havia de morrer, até se confessar." (IANTT DRCA, mç. 9, doc 8 : 19) Este episódio se passou no navio Nossa Senhora da Conceição em setembro de 1627.

\footnotetext{
${ }^{4}$ A concordância gramatical presente na escrita são originárias do documento transcrito.

5 As bolsas de mandinga, eram "amuletos produzidos com elementos cristãos" no qual os negros resignificavam "os objetos cristãos mágicos-religiosos, à luz de suas culturas de origem, buscando proteção do mundo sobrenatural nas bolsas de mandinga, e principalmente soluções para os problemas deste mundo." Geralmente as bolsas de mandinga eram feitas de pano ou couro e costuradas, contendo dentro delas, elementos do cristianismo, à exemplo da hóstia consagrada, mais conhecida nas denúncias, como partícula; e elementos que, para os negros, conferiam proteção, como as orações escritas em pedaços de papel, pequenas quantidades de chumbo, pedra d'ara, cascas de alho, entre outros ingredientes. Para maiores detalhes, ver: SOUZA, Laura de Mello e. O diabo e a Terra de Santa Cruz. Feitiçaria e religiosidade popular no Brasil colonial. São Paulo, Companhia das Letras, 2009.
} 
Nicolau Miguel foi descoberto porque começou em alto-mar uma tormenta. Ele deu a dita bolsa ao piloto do navio para que esta fosse atada a nau, para que o mar se acalmasse e o barco não virasse.

A religiosidade de Nicolau Miguel é um ponto a ser analisado. Ele utilizava o amuleto para que não morresse antes de se confessar. Então, isso é uma demonstração do sincretismo religioso. O medo de morrer sem se confessar é uma crença cristã. Com isso, podemos perceber que Nicolau realmente acreditava nisso, tanto que temia morrer sem a confissão. $O$ uso do amuleto para acalmar o mar, foi provavelmente na crença de que esse tipo de objeto serviria para enfrentar todos os males. A bolsa, neste caso, serviria para dar maior força às crenças cristãs.

Portanto, podemos ver que o uso de bolsas de mandinga era bastante comum, até mesmo entre espaços preferencialmente freqüentados por brancos. Isso nos permite questionar até que ponto as pessoas eram coniventes com o uso desses amuletos. Ou seja, mesmo sendo denunciado, Nicolau Miguel sabia mais ou menos por onde caminhava. Provavelmente, ele não era o único a utilizar esse tipo de amuleto, porém foi ele que caiu nas teias da Inquisição. Mas as crenças de Nicolau Miguel só poderão ser analisadas através da denuncia feita por Manuel Correia, visto que o denunciado não tinha 
o seu depoimento tomado. Ou seja, a possibilidade existente é trabalhar com os indícios deixados pelos denunciantes.

Dessa maneira, com a análise preliminar de alguns casos que constituem as Denunciações do Reino do Congo e Angola, podemos refletir acerca de como era o cotidiano de um reino, que fazia parte de um Tribunal da Santa Inquisição. Perceber as religiosidades, crenças e costumes de uma população que estava sob a jurisdição de uma metrópole portuguesa, além de estar sob a alçada de um Tribunal Inquisitorial.

Uma maios análise poderá desvendar questões que mapeiam as mentalidades da época, assim como as reflexões que cercam as ações da Inquisição Portuguesa na África. Entender as inserções e as permanências de um Tribunal Inquisitorial, num território no qual a cristianização e as tradições religiosas se uniam e aculturavam numa miscigenação própria e única. Ademais, questões como estas e ainda outras podem surgir com novas respostas, com novos olhares sobre o funcionamento da Santa Inquisição na África.

\section{Fonte}

IANTT - Instituto Arquivo Nacional da Torre do Tombo.

Código de referência: PT/TT/TSO-IL/040/0009.00008

Título: "Denunciações do Reino do Congo e Angola" 
Datas: c.a.1620/c.a.1632

Nível de descrição: Documento composto. Dimensão e suporte 107 f., (17 f. em branco); papel

História custodial: $\operatorname{Em} 2009$, este documento foi numerado seqüencialmente, mantendo a exata ordem encontrada, de modo a possibilitar o mínimo de controlo físico. Localização física: Tribunal do Santo Ofício, Inquisição de Lisboa, mç. 9 , doc. 8

Existência e localização de cópias: Cópia microfilmada. Portugal, Torre do Tombo, mf.7423

URL http://digitarq.dgarq.gov.pt?ID=2318699

\section{Bibliografia}

ALENCASTRO, Luiz Felipe de. O trato dos viventes: Formação do Brasil no Atlântico Sul, séculos XVI e XVII. São Paulo: Companhia das Letras, 2000.

BETHENCOURT, Francisco. História das Inquisições: Portugal, Espanha e Itália - Séculos XV-XIX. São Paulo: Companhia das Letras, 2000.

BETHENCOURT, Francisco; HAVIK, Philip J. A África e a Inquisição portuguesa: novas perspectivas. Revista Lusófona de Ciência das Religiões. Lisboa, n. 5/6. 2004.

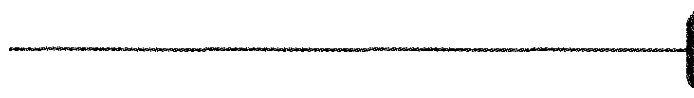


GINZBURG, Carlo. História Noturna. Decifrando o Sabá. São Paulo: Companhia das Letras, 1991.

HORTA, José Augusto N. Silva. A inquisição em Angola e Congo: O Inquérito de 1596-98 e o Papel Mediador das Justiças Locais. In.: Arqueologia do Estado. Primeiras Jornadas sobre formas de organização e exercício dos poderes na Europa do Sul, Séculos XIII - XVIII. Vol. 1, Lisboa. História \& Crítica, 1988. Pág. 387-415

LOVEJOY, Paul. A escravidão na África - uma história de suas transformações. Rio de Janeiro. Civilização Brasileira, 2002.

MARCUSSI, Alexandre. Iniciações rituais nas Minas Gerais do século XVIII: os calundus de Luzia Pinta. Maringá, PR. Revista Brasileira de História das Religiões, vol.1,n 3, 2009.

MOTT, Luiz. O calundu-Angola de Luzia Pinta: Sabará, 1739. Revista do IAC, Ouro Preto, n. 1, p. 73-82, dez 1994

NOGUEIRA, Carlos Roberto F. O diabo no imaginário cristão. 2. Ed. Bauru, SP: EDUSC, 2002.

RIBAS, Rogério de Oliveira. Cide Abdella: um marabuto na corte de D. João III. In: D. João III e o Império. Actas do Congresso Internacional comemorativo do seu nascimento. Lisboa. Centro de História de Além-mar. 2004

SANTOS, Vanicléia Silva. As bolsas de mandinga no espaço Atlântico: Século XVIII. Tese (Doutorado - Programa de Pós- 
Graduação em História Social. Área de concentração: História Social) - Departamento de História da Faculdade de Filosofia, Letras e Ciências Humanas da Universidade de São Paulo. São Paulo, 2008. SILVA, Alberto da Costa e. Angola. In: A manilha e o Libambo: a África e a escravidão, de 1500 a 1700. Rio de Janeiro. Nova Fronteira, 2002. Pág. 407-450

SOUZA, Grayce Mayre Bonfim. Para remédios das almas: Comissários, qualificadores e notários da Inquisição Portuguesa na Bahia (1692-1804). Tese (Doutorado). Programa de Pós-Graduação em História Social, Salvador, 2009.

SOUZA, Laura de Mello. O diabo e a Terra de Santa Cruz. Feitiçaria e religiosidade popular no Brasil colonial. São Paulo: Companhia das Letras, 2009. 